\title{
Kansas State University
}

\section{DOE/KEURP Site Operator Program}

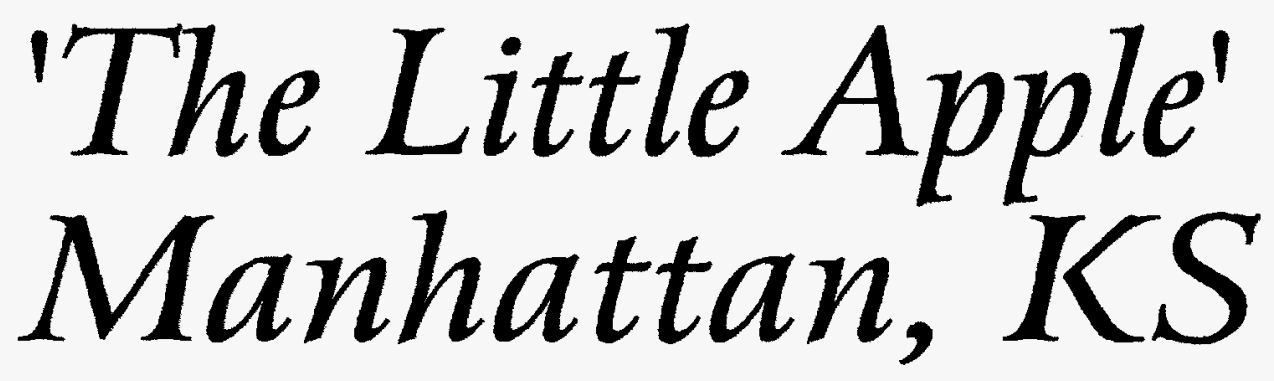

June 25, 1995

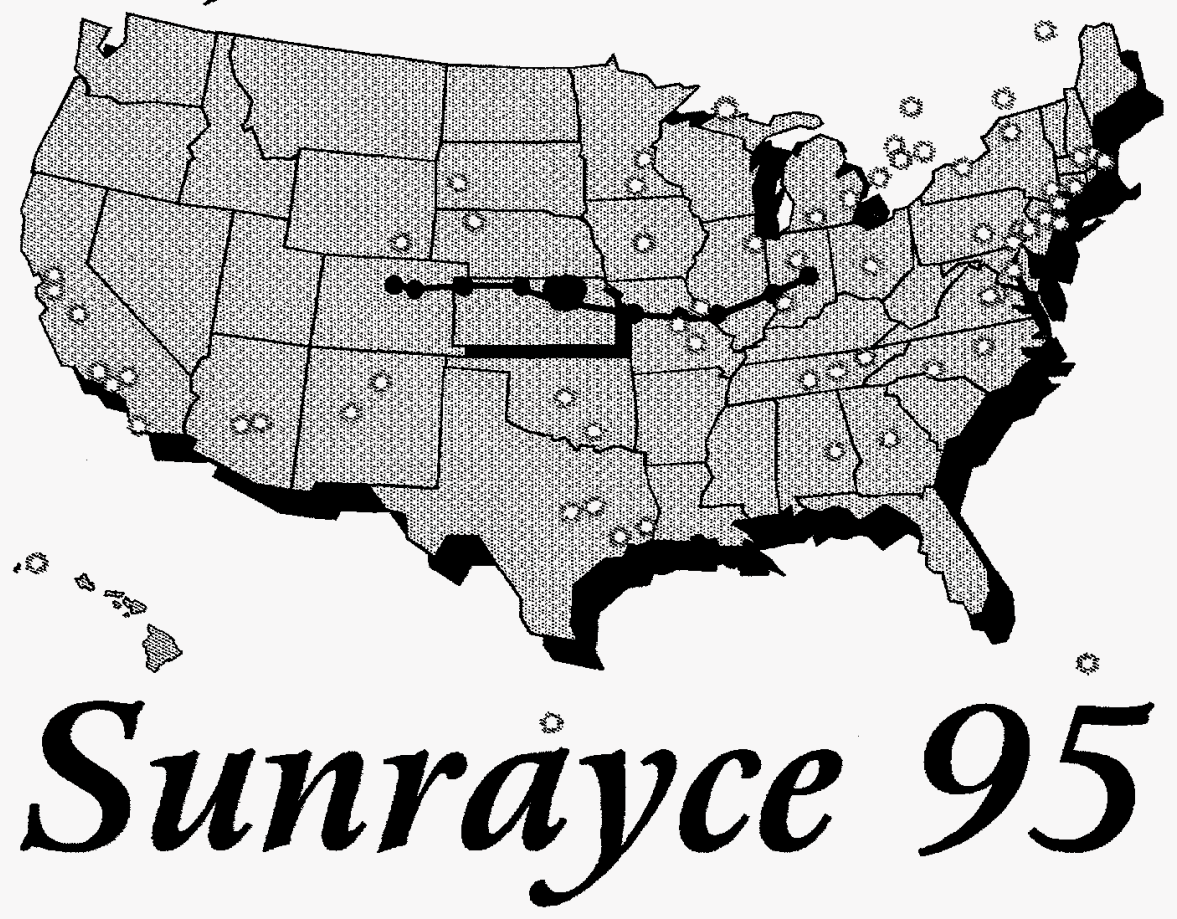

Prepared by:

James R. Hague

Director, Electric Vehicle Program

Jenifer Hague

Student Assistant
Jill Dirksen

Student Assistant

Kansas State University

219 D Seaton Hall

Manhattan, KS 66506

Phone (913) 532-5617

Fax (913) 532-5661 


\section{DISCLAIMER}

Portions of this document may be illegible in electronic image products. Images are produced from the best available original document. 


\section{DISCLAIMER}

This report was prepared as an account of work sponsored by an agency of the United States Government. Neither the United States Government nor any agency thereof, nor any of their employees, makes any warranty, express or implied, or assumes any legal liability or responsibility for the accuracy, completeness, or usefulness of any information, apparatus, product, or process disclosed, or represents that its use would not infringe privately owned rights. Reference herein to any specific commercial product, process, or service by trade name, trademark, manufacturer, or otherwise does not necessarily constitute or imply its endorsement, recommendation, or favoring by the United States Government or any agency thereof. The views and opinions of authors expressed herein do not necessarily state or reflect those of the United States Government or any agency thereof. 


\section{TABLE OF CONTENTS}

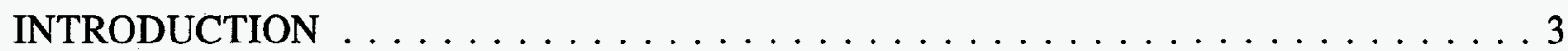

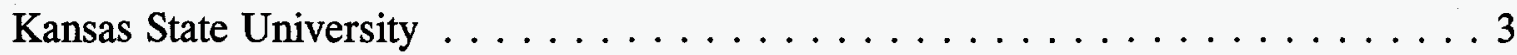

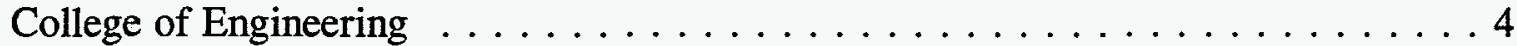

Kansas Electric Utilities Research Program $\ldots \ldots \ldots \ldots \ldots \ldots \ldots$

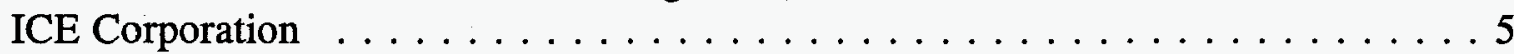

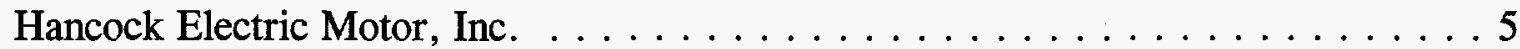

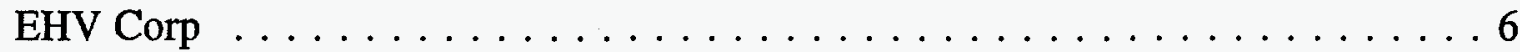

Advanced Manufacturing Institute $\ldots \ldots \ldots \ldots \ldots \ldots \ldots$

KPL, A Western Resources Company . . . . . . . . . . . . . . . . 6

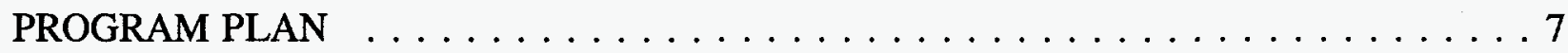

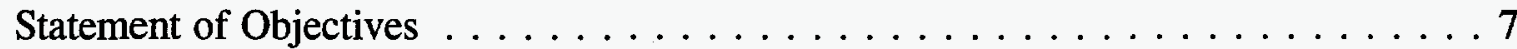

Short Term Goals . . . . . . . . . . . . . . . . . . . . 7

Long Term Goals $\ldots \ldots \ldots \ldots \ldots \ldots \ldots \ldots \ldots \ldots$

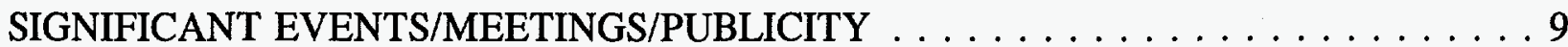

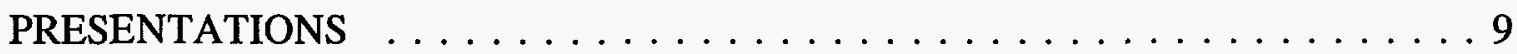

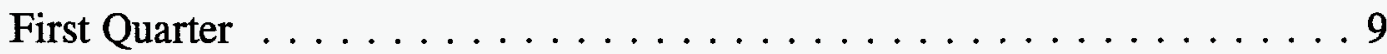

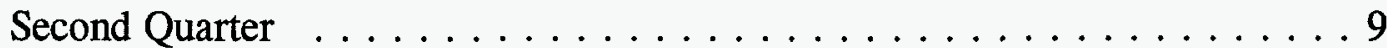

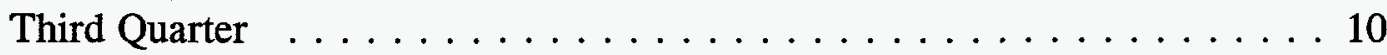

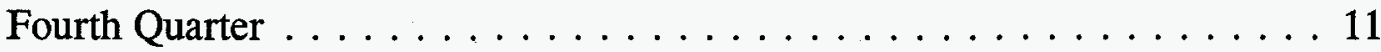

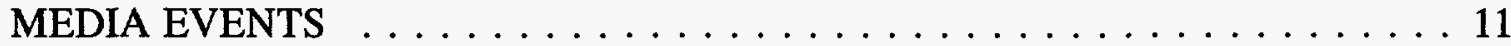

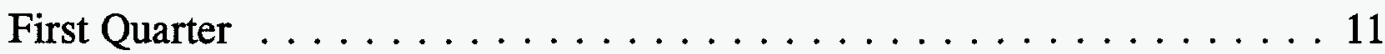

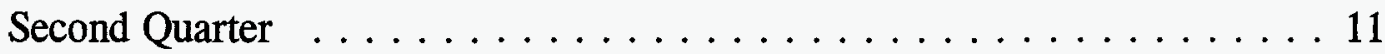

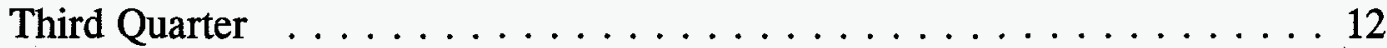

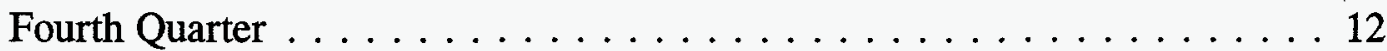

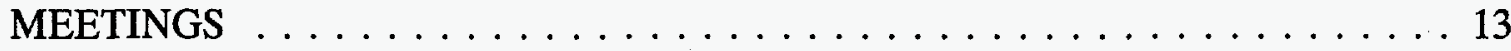

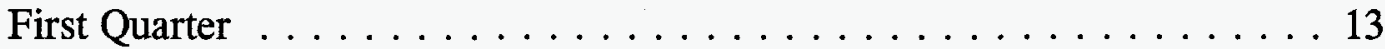

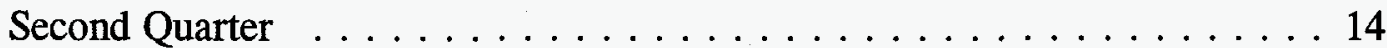

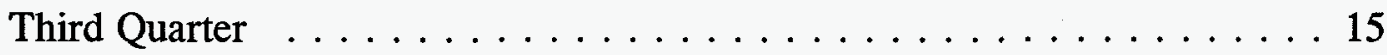

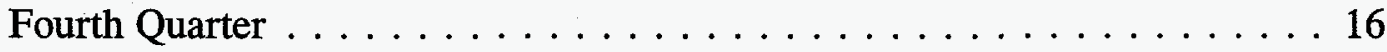

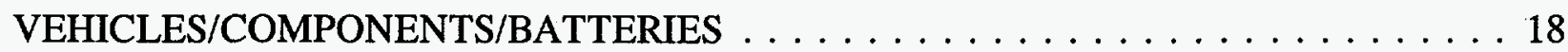

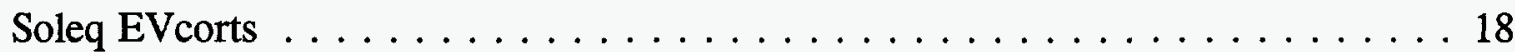

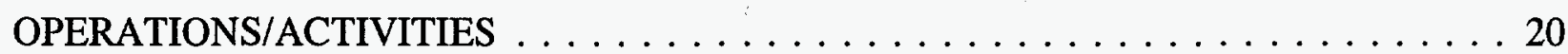

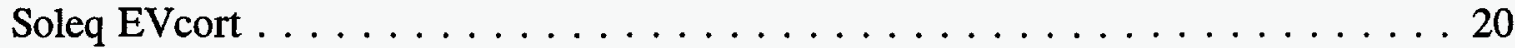

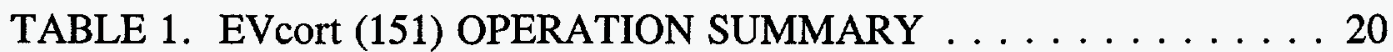

TABLE 2. EVcort (152) OPERATION SUMMARY . . . . . . . . 21 


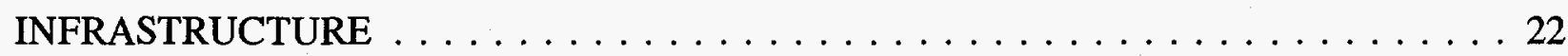

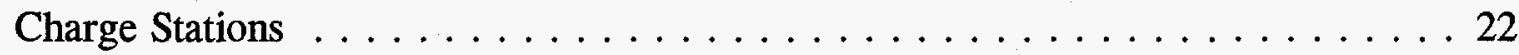

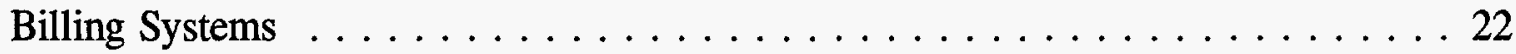

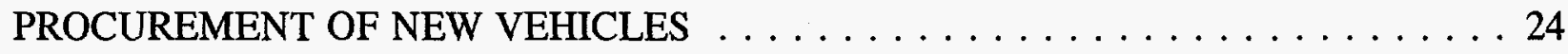

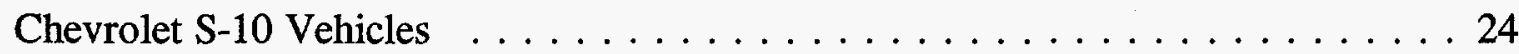

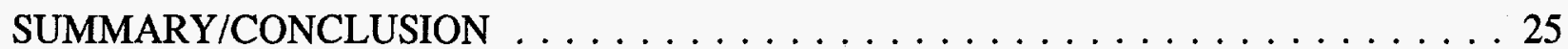




\section{INTRODUCTION}

\section{Kansas State University}

Kansas State University was founded in February 1863 as a land-grant institution under the Morrill Act. It has evolved into an internationally recognized comprehensive university. Kansas State University offers excellent academic programs, a lively intellectual and cultural atmosphere, and a friendly campus to its community of approximately 17,500 undergraduate and 3,500 graduate students.

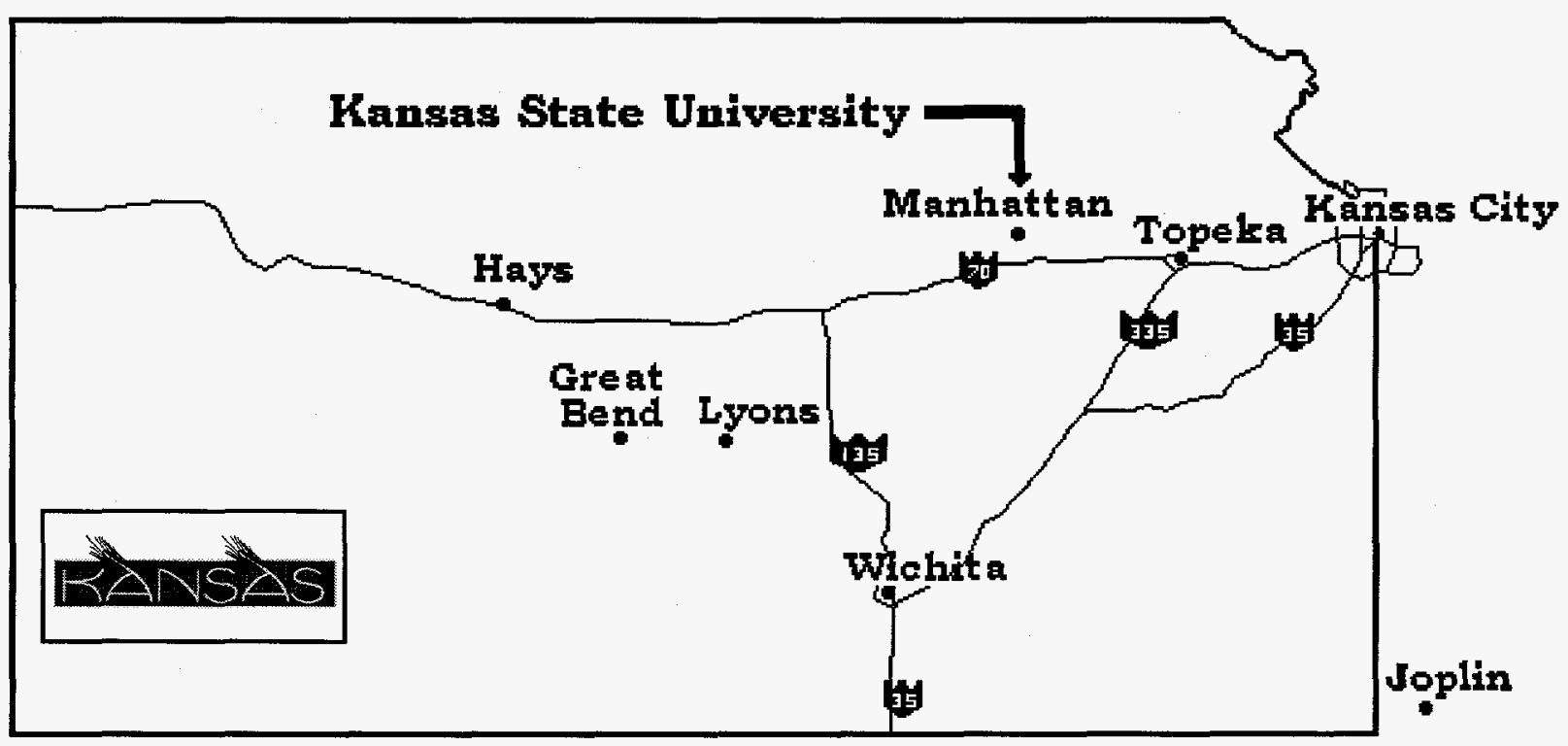

The 668-acre main campus is in the northeastern Kansas community of Manhattan. Manhattan is approximately fifty miles to the west of the state's Capital of Topeka and eighty-five miles west of Kansas City. For reference purposes, a state map is provided above. The university offers more than 200 undergraduate degree programs and options, 60 master's degree programs, and 42 doctoral programs within its eight colleges: agriculture, arts and sciences, architecture and design, business administration, education, engineering, human ecology, and veterinary medicine.

K-State accomplishments have had extensive effects: astronaut space gloves and the waterpurifying system used on the NASA space shuttles were developed here; two Kansas Centers of Excellence, one in manufacturing and one in value added research are located on campus; the University has national hazardous substance and atomic physics research programs; the Konza Prairie Research Natural Area is used for a National Science Foundation ecological research study on erosion and prairie mammals; and a major national center for basic cancer research is at $\mathrm{K}$ State.

Paul Harvey, in a special commentary, labeled Kansas State University the "student scholar capital 
of the world." This statement was made based on the number of Rhodes, Truman, Fulbright, Mellon, Goldwater, Phi Beta Kappa, Rotary International, Javits, Tilden-Snow, and Marshall scholarships awarded to K-State students over the past sixteen years.

\section{College of Engineering}

The College of Engineering at Kansas State University has excellent programs in every aspect of engineering. The college has an enrollment of 2,600 undergraduates and 300

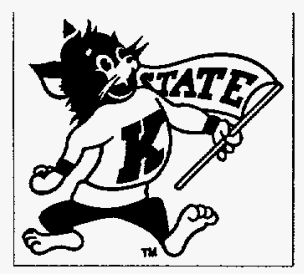
graduate students. K-State offers degrees or options in almost every major field of engineering, including aerospace, agricultural, architectural, biomedical, chemical, civil, computer, construction science, electrical, engineering technology, industrial, manufacturing, mechanical, and nuclear.

Kansas State's College of Engineering is recognized nationally for the quality of both its students and faculty. Approximately half of all K-State's National Merit Scholarship finalists enroll in the college.

For six consecutive years, one or more K-State students have been selected for Washington, D.C. internships in the Engineering Program. Each year WISE selects a group of only 14 to 16 engineering students from more than 200 engineering colleges across the nation. These students work on engineering and technology public policy issues.

Ray Dempsey, a senior in industrial engineering, was selected as the 1989-90 outstanding black engineer by the National Society of Black Engineers.

K-State's College of Engineering is one of 10 colleges in the country to be cited twice by the National Society of Professional Engineers for its outstanding professional programs. The chapters of the departmental professional sectors have received national recognition. Most recently, agricultural engineering, civil engineering, and construction science have been designated as the outstanding student chapters in the nation.

\section{Kansas Electric Utilities Research Program}

Formed on July 15, 1981, the goal of this program is to undertake applied research and development projects that may enhance reliability and minimize the cost of electric service in Kansas. The Kansas Electric Utilities Research Program (KEURP) is a contractual joint venture between seven major electric utilities that serve the residents of the State of Kansas:

KPL, A Western Resources Company, Topeka, Kansas Kansas City Power \& Light Company, Kansas City, Missouri KG\&E, A Western Resources Company, Wichita, Kansas WestPlains Energy, Great Bend, Kansas The Empire District Electric Company, Joplin, Missouri Midwest Energy, Inc., Hays, Kansas Sunflower Electric Power Corp., Hays, Kansas 
The establishment of KEURP was made possible by the Kansas Corporation Commission (KCC). KCC allowed Kansas electric utilities to include research and development (R\&D) costs in their operating expenses, including dues to the Electric Power Research Institute (EPRI).

Kansas' universities play a unique role in KEURP with representation on the executive, technical and advisory committees of the program. The universities receive significant direct and indirect support from KEURP through direct-funded projects as well as KEURP/EPRI co-funded projects. KEURP is working with EPRI researchers on projects to develop or expand Kansans' knowledge and expertise in the fields of high technology and economic development. KEURP is a major source of funding in the electric/hybrid vehicle demonstration program.

\section{ICE Corporation}

ICE Corporation is an original equipment electronics manufacturer. Seventeen employees produce solid state and microprocessor control systems for the aircraft, agriculture, and

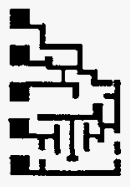
oil industries. Complete design and manufacturing facilities are located in Manhattan, Kansas. ICE continues its efforts on research, design, development, and production of $\mathrm{AC}$ and $\mathrm{DC}$ motor controller systems. Products are used in a number of different industries from assisting the disabled in achieving a higher quality of life, to advancing the state of robotics, to assisting industries in specific motorized applications.

ICE Corporation continues its work on high technology power switches. ICE designed and developed high power switches and is working with a number of companies to provide specific applications for this product. ICE is committed to assisting K-State's electric vehicle program in vehicle demonstrations, research, testing, and evaluation of product. ICE provided a letter of commitment for $\$ 2,000.00$ per year for the five year contract as a cosponsor to the Department of Energy's Site Operator Users Task Force.

\section{Hancock Electric Motor, Inc.}

Hancock Electric Motor (HEM) is one of the largest electric motor repair facilities in the state of Kansas. The shop facilities in Lyons, Kansas, contain a welding shop Hancock (metalizing, welding, and chroming facilities), a machine shop (500 ton horizontal press, 250 ton vertical press, horizontal boring machine, and a 60 -inch engine lathe), dynamic balancing, vacuum pressure impregnation system, and capabilities to rewind electric motors with 13,200 volt 10,000 horsepower ratings. AC motors, DC motors, synchronous motors and generators, pumps, traction motors, locomotive main generators, alternators, generators, semihermetic motors, and haul truck wheel motors are all within the realm of HEM's repair capability. Further impedance testing can be done with the $750 \mathrm{KVA}$ core loss tester. Labor rates run $\$ 40$ /hour with design and consulting costs at $\$ 75 /$ hour plus expenses. HEM is committed to helping KSU in EHV demonstration, research, testing, and evaluation and has provided a letter of commitment for $\$ 2,000.00$ per year for the life of DOE's 
contract. HEM has recently taken steps to allow production of electric vehicles to meet growing market demands within the Midwest region.

\section{EHV Corp}

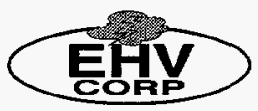

EHV Corp is a Kansas Company specializing in manufacturing infrastructure components for the electric vehicle industry. The home office of EHV Corp is located in Manhattan, Kansas. Manufacturing of electrical and mechanical parts is accomplished by other companies while EHV Corp is primarily concerned with the research and development of new products and the assembly of existing products. EHV Corp has received an economic development grant from the state of Kansas for development of its EDD-7 charging station. Further, EHV Corp has developed proposals to DOE and EPRI concerning its products. EHV Corp recently delivered its first meter for testing by a governmental laboratory. EHV Corp is hoping to establish a national demonstration program for curbside recharging within the next twelve months. This project would involve the Federal Government, Underwriters Laboratory, and major utilities in establishing curbside charging stations in major urban centers. EHV Corp has provided a letter of commitment for $\$ 10,000.00$ to establish this national demonstration program.

\section{Advanced Manufacturing Institute}

The Advanced Manufacturing Institute (AMI) was established to promote technology transfer in the state of Kansas. AMI's goal is to develop and transfer new technology to commercial manufacturers. This Center of Excellence, located in the College of Engineering, is funded by the Kansas Technology Enterprise Corporation that derives its funding through the state lottery system. AMI strives to increase economic development through research and technology transfer in advanced areas of manufacturing technology. The institute's objectives are to help Kansas companies by working with them to expand services, design new products, and increase productivity. Special emphasis is given to the needs of smaller companies.

\section{KPL, A Western Resources Company}

Kansas Power and Light Company is part of Western Resources. Western Resources supplies electricity and natural gas to most of Kansas and portions of Missouri and

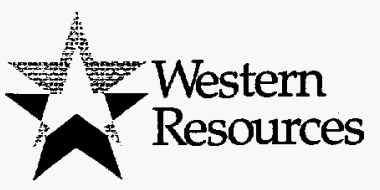
Oklahoma. Although KPL provides funding to K-State's electric vehicle program through its membership in KEURP, it provides additional funding directly to $\mathrm{K}-$ State in support of electric vehicle programs. KPL has been involved with $\mathrm{K}$-State during the last fifteen years in providing support for electric vehicles. KPL engineers are working with K-State to develop a national demonstration program to evaluate infrastructure technology for electric vehicles. 


\section{PROGRAM PLAN \\ Statement of Objectives}

\section{Short Term Goals (1 year)}

1. Participate in the Department of Energy's Site Operator Program.

2. Evaluate Electric/Hybrid Vehicle technology through purchase of vehicles.

3. Collect user data and develop historical perspective on vehicle requirements.

4. Provide reports to DOE and KEURP on EHV data collected.

\section{Long Term Goals (5 years)}

1. Assist the nation in reversing environmental trends concerning air quality.

2. Establish Kansas State University as a national site for testing, evaluating and reporting on new technology electric and hybrid vehicle technology.

a) Site will test vehicles through accelerated life use.

b) Site will determine long range reliability through dedicated testing.

c) Site will determine life cycle cost of such vehicles.

d) Reports will be generated for fleet manager use in determining "buy decisions".

e) All testing will be done in "real-time" to ensure meaningful data is collected.

Kansas State University, with funding support from federal, state, public, and private companies, is participating in the Department of Energy's Electric Vehicle Site Operator Program. Through participation in this program, Kansas State is displaying, testing, and evaluating electric or hybrid vehicle technology. This participation will provide organizations the opportunity to examine the latest EHV prototypes under actual operating conditions. KSU now has two electric cars. Both are electric conversion vehicles from Soleq Corporation out of Chicago. KSU in conjunction with KEURP also initiated procurement for the purchase of four (4) Chevy S-10 pickup trucks. Since the supplier, GE-Spartan, has canceled its effort concerning the production of these vehicles and no other appropriate source has been found to date, K-State and the Kansas Utilities are searching for an alternate supplier of electric vehicle technology. 
The Soleq EVcorts have not been signed to illustrate to the public that it is an electric vehicle. Magnetic signs have been made for special functions to ensure sponsor support is recognized and acknowledged. As soon as TDM's Ford Ranger electric vehicles are delivered they will be used throughout the state by utility companies that are participating with K-State's Site Operator Program. 


\section{SIGNIFICANT EVENTS/MEETINGS/PUBLICITY}

\section{PRESENTATIONS}

\section{First Quarter}

September 24

Department of Natural Resources

Columbia, $M O$

Two student assistants, Jarrett Thummel and Jenifer Hague, at the request of Kansas City Power \& Light Company, transported a Soleq EVcort to Columbia, MO for an Alternative Energy show. The show was held at Rock Bridge State Park just outside of Columbia. The Missouri DNR provided a variety of educational exhibits for the public. Among these were other alternative fuel vehicles including propane, natural gas, and solar. The event was well organized but, "Mother Nature" did not cooperate. Rain and cold temperatures inhibited public participation and the event was canceled early in the afternoon.

\section{Second Quarter}

October $12 \& 13$

Continental Conference

Kansas City, MO

The Kansas Corporation Commission, in conjunction with other State Commissions, sponsored a three-day event on Alternate Fuel Energy Programs. Professor Jim Hague was invited to be a guest speaker on electric vehicles. Further, Kansas State University provided a display including a Ride-n-Drive showcasing the Soleq EVcort.

October 19

Alternative Fuel Vehicle Seminar

Wichita, KS Western Resources and KG\&E sponsored a one day seminar on alternative fuel vehicles at Beech Activity Center in Wichita, KS. Jim Hague, in addition to discussing electric vehicles, focused discussion toward K-State's funding goals and the technological accomplishments that have resulted from receiving funding. Other speakers that attended were John Morelock, KCC Alternative Fuels Coordinator, Lee Eisenhauer, V.P. of Propane Marketers, Wade Wright, Director of Residential \& Commercial Marketing at Western Resources, and Greg Krissek, State Board of Agriculture. Kansas State University provided a Ride-n-Drive for executives from the aircraft industry.

October 19

East High School

Kansas City, $M O$

At the request of Kansas City Power and Light Company, K-State participated with an electric vehicle presentation at the East High School's Alternative Fuels Vehicle Expo. Included in the Expo were vehicles propelled by propane, compressed natural gas, soy diesel, and solar energy. Nice weather prompted the success of the Expo as close to 500 students were 
in attendance. This was the second year KSU's electric vehicle was requested to be part of the alternative fuel show at this magnet school's program.

October 24-26

Central Electric Vehicle Symposium

Oklahoma City, OK

Upon request of the Central Electric Vehicle Coalition, K-State provided a display and exhibit for show at the Myriad Convention Center in Oklahoma City. In attendance were top decision makers such as fleet owners, educators, electric utility executives, government officials as well as vehicle component manufacturers. K-State, with support from Western Resources, provided an electric vehicle to participate in the Ride-n-Drive exhibit.

November 1

Fort Riley High School

Fort Riley, KS Bob Mullen, teacher of the Fort Riley High School technology class, requested K-State give a presentation on electric vehicles to his classes. KState responded by taking a vehicle to the school and providing four hours of demonstration and exhibition. Included were approximately 140 students, faculty, and administration members. In order to become eligible for vehicle rides, the students were required to write a paper on why they would like to find out more about electric vehicles. The best papers, as selected by Mr. Mullen, enabled successful authors the opportunity to ride in KSU's electric vehicle. Faculty members were permitted to ride without any prerequisite.

November 8

Northern Hills Jr. High School

Topeka, KS Wade Graves of Western Resources requested the assistance of K-State to provide support in the demonstration of electric vehicles to seventh $\&$ eighth grade students at Topeka Elementary. Mr. Graves made a presentation to the class and discussed Western Resources commitment to testing, promoting, and advancing electric vehicle technology. After the short presentation by Mr. Graves, students and faculty were offered to experience a ride in this new technology vehicle. All in attendance seemed very enthusiastic about the future of electric vehicles.

\section{Third Quarter}

January 13

Manhattan Area Amateur Radio Society

Manhattan, KS

Professor Hague and K-State students presented a slide show and demonstration on EVs to the Manhattan Area Amateur Radio Society. This is the second time K-State's electric vehicle program was requested to provide a presentation. It was particularly appropriate since many of the Radio Society members will serve as volunteers for this summer's Sunrayce '95 event being hosted on Kansas State University's Campus. 


\section{Fourth Quarter}

May 15

Manhattan Town Center

Manhattan, KS

Kansas State University was asked by the Kansas Seat Belt Association to provide a static display of our electric vehicle. The vehicle was used to help draw attention to a day long demonstration and display of local rescue equipment currently in use. Included in the car's display was a presentation of special precautions to be taken during rescue and recovery of persons involved in accidents with alternative fuel vehicles. The purpose of this display was to inform the public that electric vehicles are a safe alternative to vehicles currently in use.

May 20

Little Apple Car Show

Manhattan, $K S$

The electric vehicle was displayed to the public in a local park during a state wide gathering of exotic and antique cars. A large percentage of the local population was able to view and ask questions about current and future trends in alternative fuel transportation.

MEDIA EVENTS

\section{First Quarter}

None Scheduled

\section{Second Quarter}

October $12 \& 13 \quad$ Continental Conference

Kansas City, $M O$

The Kansas Corporation Commission, in conjunction with other State Commissions, sponsored a three-day event on Alternate Fuel Energy Programs. The Kansas and Missouri utility CEO's unveiled the new GE/Spartan S-10 vehicle during this conference. Kansas State University also had a display including a Ride-n-Drive.

October 19

East High School

Kansas City, $M O$

Representatives from East High School, in order to further promote alternate fuel vehicles, prompted members of the press including local Kansas City television stations to attend the Alternate Fuels Vehicle Expo. K-State's vehicle attracted much attention as it was the only electric vehicle participating in the Expo. 
Professor Hague participated in the twelfth international electric vehicle symposium held in Disneyland, California. Mr. Dale Myers, from Kansas City Power and Light was also in attendance at this event. Over fifty electric vehicles from around the world were on display or available for driving. Professor Hague chaired a session on infrastructure at this event and further provided a booth highlight efforts by KEURP, Western Resources, and Kansas State University to advance EV technology.

\section{Third Quarter}

March 3-5

APS Race

Phoenix, $A Z$

Although no representative from Kansas State University's electric vehicle program attended this year's Arizona Public Service Race, EHV Corp, as part of the KSU Program, did provide charge stations for use in the race. This is the fourth consecutive year that APS has placed an order for EHV Corp's charge stations in order to meet increased demand of these devices during race events.

\section{Fourth Quarter}

June $23 \& 24$

Sunrayce '95

Longview Community College, $M O$ One of Kansas State University's two electric vehicles was on display for the public when Sunrayce '95 participants arrived for a two day layover. Those involved in the race also had a chance to view our vehicle and make assessments of the transitions necessary to move from special purpose experimental vehicles to those that would be embraced by the general population.

June $25 \& 26$

Sunrayce '95

Manhattan, KS

K-State and the City of Manhattan hosted day six for the Department of Energy's national solar electric car race. The committee met regularly to secure plans for security, accommodations, food, first aid, activities/events, volunteers, publicity, and communication. The 1,000 students, DOE, GM, and other sponsors that visited K-State's campus characterized the event in Manhattan as "undoubtedly the best organized, best hospitality, and best accommodations of any they have had, or hope to have on the race route from Indianapolis, Indiana to Golden, Colorado." This event demonstrated to the students the importance of engineering, solar energy, advanced technologies, and public awareness to their careers. One of the University's EVcorts was on display for the public to view and ask questions about during the race. The success of Sunrayce '95 in Manhattan was due to the support of Western Resources, Edith Stunkel, Mayor of Manhattan, Lt. Governor Frahm, KSU's President Wefald, and the volunteers that gave so freely of their time. 


\section{MEETINGS}

\section{First Quarter}

July $12 \& 13$

July 14

July 25 - Aug 1

August 26

August 3-4

September 6
Smart Card Technology

Los Angeles, $C A$

Professor Hague attended a two-day event on Smart Card technology. Debit cards are already well recognized in Europe for financial transactions and are now beginning to appear in the United States. One of the first applications to use Smart Cards in the United States was EHV Corp's Connective Charge Station, the EDD-7. Professor Hague believes that in the next five years Smart Card technology will have a significant impact on billing within utility companies across America.

KEURP Electric Vehicle Task Force

Manhattan, KS

The KEURP Electric Vehicle Task Force met to discuss the state of electric vehicle projects now underway. No specific action was taken but a report was given on the competitive nature of off-road EV technology.

\section{European Tour}

Professor Hague visited Paris, France, Cambridge, England, and Graz, Austria to discuss electric vehicle projects planned or now underway with Kansas State University.

Eagle Picher

Joplin, $M O$

K-State retired the DSEP Minivan to Hancock Electric in Lyons, Kansas during the past year. Because Hancock Electric had no way of disposing of the expended nickel-iron batteries, they were not included in the transfer of the vehicle. The battery pack was removed and transported to Eagle Picher, Joplin, Missouri. Eagle Picher will recycle the batteries and use them in future battery manufacturing.

SOUTF Meeting

Estes Park, $C O$

The quarterly meeting of the Site Operator Users Task Force was held in Colorado. Major topics of discussion were the relationship with EV America, replacement of Jim Hague as Chair of the Site Operator Users Task Force, nominations for new Chair, and testing of EV America sanctioned vehicles.

G-Van to Eagle Picher

Joplin, $M O$

The G-Van was delivered to the Eagle Picher plant in Joplin, Missouri as a test vehicle for research on electric vehicle battery technology. Due to the excessive weight of the vehicle, K-State requested assistance from Western Resources to transport the G-Van. K-State would like to thank Western Resources for providing a truck and driver for the shipment. We wish Eagle 
Picher great success in using the G-Van for research purposes.

\section{Second Quarter}

October 6

October 7

October 21

November $9 \& 10$
NIST Advanced Technology Conference

Topeka, KS The National Institute of Standards and the Kansas Technology Enterprise Corporation sponsored a one day event on writing proposals for the advanced technology program grant. Partnership activities, for improving the opportunity for successful proposal selection, was discussed. Kansas, as a state, has never had a proposal selected for funding since this federal program was introduced.

KEURP Transportation Advisory Meeting

Topeka, KS Professor Hague met with the Kansas Electric Utilities Research Program Transportation Advisory Group to discuss upcoming activities for 1995. Discussions centered around expected DOE funding levels, types of vehicles to be purchased in the coming years, status of vehicles purchased to date, and infrastructure requirements.

Sunrayce '95 Committee Meeting

Manhattan, KS

Kansas State is getting the ball rolling as quickly as possible to make arrangements for the annual Sunrayce event. Kansas State University has been selected as a "stop site" for the race that will start in June 1995. The solar vehicle race is making an overnight stop June 26 at the Kansas State University campus. Extensive planning and coordination will be required to handle the 1,000 students and sixty solar vehicles descending upon Manhattan. KSU wants to ensure local city and county officials are included in this process.

SOUTF Meeting

Washington, D.C.

The Site Operator Users Task Force meeting was held in Washington, D.C. in conjunction with the annual ETC year end meeting and the EV America review of data on testing of selected electric vehicles. The meeting was so large with little or no structure to the meeting that it became a "general discussion" with little accomplished. Several representatives became disgruntled and left the meeting early. It would seem that in the future, if large groups are organized at the national level, smaller working groups should bring information to the main body. EV America and SOUTF have scheduled another meeting for January 19 and 20 in Kansas City, Missouri. This group is expected to be even larger. 


\section{Third Quarter}

January 6

January $19 \& 20$

February 21

February 22

March 10

March 15
AMI Conference

Manhattan, KS

The annual Advanced Manufacturing Institute Conference was held on Kansas State University's campus. Manufacturer's from across Kansas and throughout the region visit Kansas State University to attend seminars and demonstrations on the latest manufacturing techniques. EHV Corp and Kansas State University's electric vehicle program were highlighted during this day long event.

DOE Site Operator \& EV America

Kansas City, $M O$

Kansas City Power and Light hosted a meeting of DOE Site Operator \& EV America participants at Kansas City International Airport. The meeting was a round table discussion of electric vehicle events. U.S. Electricar presented a plan on how they would handle the repair and upgrade of electric vehicles already delivered to customers. The next meeting, it was decided, would be for Site Operator Program participants and would be held in Denver, CO.

KEURP Advisory Council

Topeka, KS

The KEURP advisory council met to discuss options on what electric vehicles would be purchased to replace the canceled GE-Spartan vehicles. No definitive solution was agreed upon because DOE must concur with any action taken by the group.

Sunrayce95

Manhattan, $K S$ Kansas State University will serve as one of the host sites for the Department of Energy's national solar electric car race. As such, a college committee meets on a regular basis to ensure strong support for the 1,000 students, DOE, GM, and other sponsors who will visit K-State's campus June 25 - 26, 1995.

Wamego Science Fair

Wamego, KS

Professor Hague served as a Judge at the Wamego High School Science Fair. One Science Fair category included alternate fuel vehicles. From the number of participants that formed their projects around electric drive and electric vehicle technology, DOE's programs are having an impact on the young minds in America.

KCREA Electric Transportation in the 21st Century

Manhattan, KS

Professor Hague presented information about "on-road" electric vehicle transportation to Kansas' Rural Electric Cooperative members. The Kansas Electric Utility Research Program also sponsored a discussion about "offroad" technology and its immediate economic viability to the "bottom line" in industrial application. The programs electric vehicles were unavailable for this demonstration due to repairs being accomplished in Chicago. 
Kansas City Power \& Light, in conjunction with Swope Park Zoo is looking at the possibility of implementing electric vehicles into the Zoo and KC Park fleet. An initial meeting was held at the Park's Administration Offices to discuss needs, logistics, cost, and opportunity to introduce electric vehicle and solar panels into the planning process. A point paper was developed by Professor Hague and the next meeting is scheduled for late May or early June.

\section{Fourth Quarter}

June 8

June 12

June 26-28

June 28-29
TDM/Ford Meeting

Detroit, $M I$

A steering committee meeting was held at Troy Design and Manufacturing's facility in Redford. The purpose of this meeting was for interested utilities to assist TDM in laying out the design and project management for TDM's Ford Ranger Electric Vehicle. Topics reviewed included infrastructure support for vehicles, vehicle design, motor controller capabilities, and strategic alliances that should be in place as initial production vehicles are delivered to customers. TDM, based on prior performance, is expected to be the first Qualified Vehicle Manufacturer (QVM) authorized to produced zero emission vehicles by any of the Big Three. TDM is already a certified QVM for natural gas vehicles.

D.C. Meeting

Washington, D.C.

A meeting was held with Deputy Secretary Bill White to discuss Kansas and its regional involvement in testing and developing electric vehicle technology. Further, a discussion was started about the relationship with TDM, Ford, and Kansas State University acting as a "hub" for Ford's QVM in collecting and distributing data for electric vehicles. It was decided by all to schedule a second meeting in Kansas City where Ford, TDM, the Kansas Electric Utilities Research Program, and other regional partners could discuss a test site developments and federal funding.

TDM Steering Committee Meeting

Detroit, $M I$

TDM hosted a Ford Ranger Electric Steering Committee Meeting. The purpose of this meeting was a follow-up to the June 8 meeting where prospective customers could provide input to the design stage of the vehicle. TDM also discussed plans finalized to date and discussed issues that remained to be resolved. The next Steering Committee Meeting was scheduled for August 4 and should finalize details for the first pre-production run. TDM also displayed their first prototype Ranger EV at this meeting.

DOE/TDM/KEURP Meeting

Kansas City, KS

A meeting was held at the Kansas City Airport to discuss TDM's proposed plant siting in the Kansas City Area. TDM wants to build a facility that will 
convert not only natural gas pickups under a Ford contract but, is also looking at the $\mathrm{KC}$ plant to produce electric vehicles for the world market. The all day event included presentations from Missouri and Kansas economic development offices as well as the utilities serving the region. The meeting concluded with a frank discussion between DOE representatives, TDM representatives, and others about DOE's involvement in funding a test center in this region. Although no final conclusions were agreed upon or arrived at, it was generally understood that DOE has little or no interest in assisting the present team with any federal support. 


\section{VEHICLES/COMPONENTS/BATTERIES}

\section{Soleq EVcorts}

The first EVcort, VIN 1FAPP15JXPW125411, which will be referred to by the Department of Energy's electric vehicle ID number 151, was delivered May 13, 1993. The second EVcort, VIN 3FAPP15J9PR106495, which will be referred to by the Department of Energy's electric vehicle ID number 152 on all the maintenance reports, was delivered to Kansas State University December 21, 1993.

Minor problems that developed on each vehicle, during the winter months, became more pronounced as vehicle range began to improve with the warmer weather. Clearly, minor problems became increasingly annoying as the vehicles are operated more often and for longer durations. Soleq Corporation has proved excellent in standing behind their warranty work and fixing problems as they have been identified. Mr. Ohba made an agreement with the University in the early stages of our program that as long as the vehicles were delivered to Chicago for repairs, there would be no charge for warranty work. To date KEURP and Kansas State University have found this arrangement to be acceptable and cost effective. The round-trip cost from Manhattan to Chicago is approximately $\$ 1,500$ to trailer an electric vehicle. The advantage of this effort is that Kansas State University students and faculty could actually visit "on site" and discuss repairs with Soleq employees. This has proved beneficial for both parties. Soleq learns from "real world" operation and Kansas State University learns "theoretical" and "proper" operation of the vehicle and its subsystems.

As was stated in the last report, EVcort 152 has been experiencing significant subsystem problems. The vehicle was returned to Soleq for repair of regenerative braking problems, heating and cooling systems problems, ground fault interruption nuisance tripping, and subsequently total vehicle system failure. Soleq has repaired each of these subsystems and vehicle 152 was returned to campus during this reporting period. All repairs have been completed on Evcort 152 and it was returned to K-State as of January 7, 1995 where it has been operated on a daily basis. Significant improvement has been noted in repaired system performance.

Many of the problems discussed in the above paragraph represent problems that are considered minor in nature; however, potential customers would not accept these vehicles as "proven technology." Without standard repair manuals and technical information being available, KSU is relegated to performing minor repairs through a "reverse engineering process." This process is time consuming, labor intensive, and therefore expensive. At some point the Department of Energy and its partners will have to require, as part of the purchase phase, that proper documentation accompany new vehicles. The problem is that manufacturers want to protect their technology in the early stages of development; therefore, obtaining proper documentation is virtually an impossible task.

EVcort 151 was delivered to Soleq on January 7, 1995 when Evcort 152 was picked up for return to K-State's campus. A number of minor problems plague vehicle 151 and made it difficult to loan, show, or utilize. Further, these problems, in combination with cold weather, limited the use of vehicle 151 to less than 10 miles per day. EVcort 151 experienced problems with ground fault 
interruption problems, regenerative braking problems, and front wheel alignment problems. These items had already been identified on vehicle 152 and vehicle 151 was repaired quickly by Soleq. At the close of this reporting period, both EVcorts have been repaired and returned to Kansas State University. All electrical system problems have been resolved, thanks to Soleq's team effort, and the cars are now fully operational. It should be noted that EVcort 152 did suffer some minor cosmetic damage when it was involved in an accident on Kansas State University's campus. Those damages have been repaired and the vehicle operates as good as new, thanks to the local Ford dealers excellent body shop work. 


\section{OPERATIONS/ACTIVITIES}

\section{Soleq EVcort}

The Soleq EVcort, DOE number 151, has been operated regularly since it was received in May 1993. During this past quarter, it has once again been active in numerous displays throughout the region. These electric vehicles certainly attract considerable interest, including television coverage, in our region. EVcort 151 experienced a failure of the regenerative braking system. K-State returned the vehicle to Soleq, Chicago, IL, for repairs. Soleq has been extremely cooperative in offering to provide service, under warranty, on KSU's vehicles. KEURP has covered the transportation costs of delivering the vehicle to Chicago and the return trip to K-State. The costs may become significant if too many "maintenance trips" are required; however, the cost of sending Soleq employees to Manhattan, KS, with limited material and tool support would prove even more expensive. Indeed, this problem focuses the need for good documentation, local repair capabilities, and spare part requirements. Included in repairs made to the EVcort 151 are: regenerative braking repair, air conditioning repair, and pre-heat system repair.

The Soleq EVcort, due to its on-board charger, is not only driven in various weather conditions, but is also able to be charged under adverse weather conditions. The EVcort is subjected to normal everyday driving conditions in and around the Manhattan area. The vehicle's performance is comparable to a standard ICE (internal combustion) vehicle. Table 1 gives a general look at data collected on the EVcort to this point.

\begin{tabular}{|c|c|c|c|c|c|c|c|}
\hline & DATE & MILES & $\begin{array}{l}\text { DAIIY } \\
\text { MILES }\end{array}$ & $\begin{array}{l}\text { NUMBER OF } \\
\text { CHARGES }\end{array}$ & $\begin{array}{c}\text { MILES } \\
\text { PER CHARGES }\end{array}$ & $\begin{array}{l}\text { KWH } \\
\text { USED }\end{array}$ & $\begin{array}{l}\text { KWH PER } \\
\text { MILE }\end{array}$ \\
\hline 1st Quarter & $09 / 30 / 94$ & 1158.5 & 19.97 & 58 & 19.97 & 584.0 & 0.50 \\
\hline 2nd Quarter & $12 / 30 / 94$ & 734.8 & 19.98 & 37 & 19.98 & 573.0 & $\overline{0.78}$ \\
\hline 3rd Quarter & $03 / 31 / 95$ & 156.4 & 19.55 & 8 & 19.55 & 112.0 & $\overline{0.72}$ \\
\hline 4th Quarter & $06 / 30 / 95$ & 816.0 & 19.43 & $\overline{42}$ & 19.43 & 447 & .55 \\
\hline TOTAL & TODATE & 6387.0 & 18.72 & 341 & 18.72 & 3950.0 & 0.62 \\
\hline
\end{tabular}

TABLE 1. EVcort (151) OPERATION SUMMARY

Assuming a price of $\$ .056 / \mathrm{Kwh}$ for electricity, and 25 miles per gallon for an internal combustion engine 1993 Ford Escort, the cost of operating the EVcort on electricity equates to $\$ .87$ per gallon of gasoline. 
Soleq EVcort, DOE number 152, the most recent addition to the K-State electric vehicle program, was operated regularly until its failure November 10,1994. The vehicle was performing as expected until a battery cable, on the main battery pack located in the rear of the car, had an internal failure and caused vehicle shut-down. As can be seen from the enclosed charts, the two vehicles (DOE 151, 152) are showing a significant difference in their performance levels. This performance gap increase could be attributed to vehicle 152's "burnt-out" battery cable. Conversations with Soleq suggest that the cable was gradually failing on the vehicle over a period of time. Vehicle 152 was at Soleq's facility from December 3, 1994 until January 7, 1995 where repairs to air conditioner, regenerative breaking and the pre-heat systems were accomplished. K-State is very appreciative to have acquired this second vehicle to make available when EVcort 151 is on the road. Additional vehicles, now planned for purchase, will be very useful in maintaining an active program in the Midwest Region. K-State is also very appreciative of KEURP for sponsoring the acquisition of a tandem axle steel bed trailer to transport the vehicles. Without this, many vehicle presentations would be limited due to transportation problems.

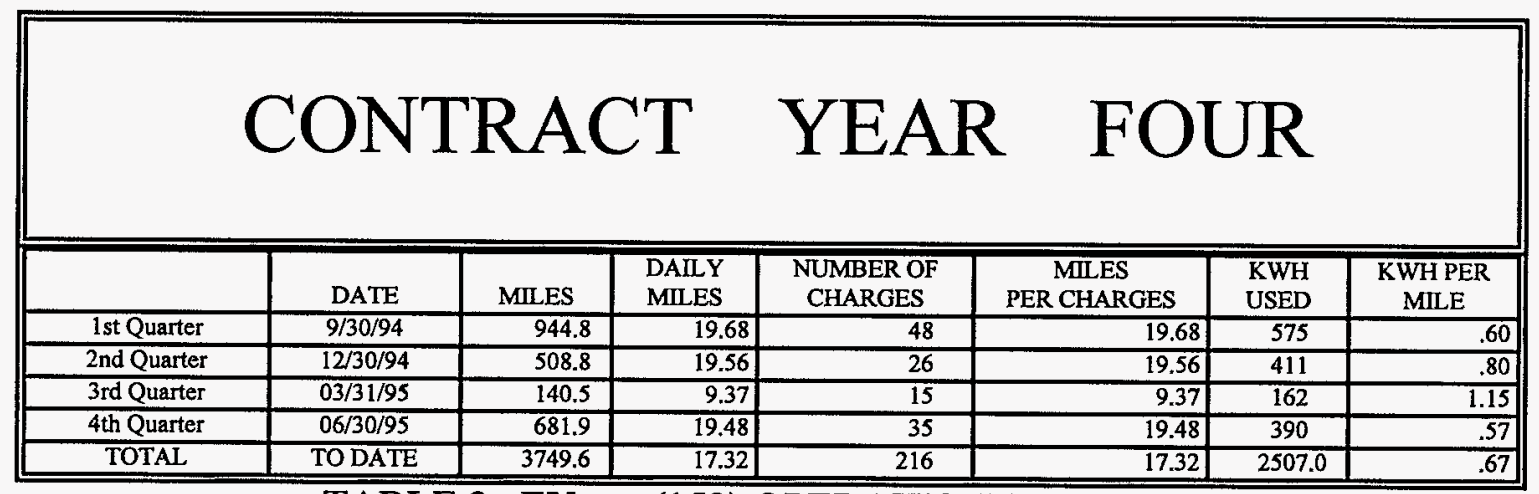

TABLE 2. EVcort (152) OPERATION SUMMARY

Assuming a price of $\$ .056 / \mathrm{Kwh}$ for electricity, and 25 miles per gallon for an internal combustion engine 1993 Ford Escort, the cost of operating the EVcort on electricity equates to $\$ .80$ per gallon of gasoline.

NOTE: EVcort 152 required a battery cable replacement. This battery cable was acting as a "heater" as its resistance (and therefore voltage drop) increased. The battery cable dissipated valuable electrical energy in the form of heat thus being consistent with an increased use of energy per mile as was indicated in the third quarter. 


\title{
INFRASTRUCTURE
}

\section{Charge Stations}

Kansas State University has continued its work with EHV Corp and KEURP in the area of infrastructure development. EHV Corp has worked with Underwriters Laboratory and the Idaho National Laboratory in testing, evaluating, and improving the quality of charge systems designed and produced in Manhattan, Kansas. Kansas State University's Advanced Manufacturing Institute provided financial support for the U.L. testing phase of the EDD-7 charge station. The charge stations were developed as part of the Department of Energy and Kansas State University's team efforts through the Site Operator Users Task Force Program.

Recently, the Electric Vehicle Research Network (EVRN), as part of a National Electric Power Research Institute demonstration program for electric vehicles, deployed twelve EHV Corp charge stations. EVRN project coordination is the responsibility of Hart, McMurphy, and Parks, with Michael Lechner serving as Project Manager. The following is a list of utility company participants that have received charge stations:

\author{
Boston Edison Company, Boston, Massachusetts \\ Centerior Energy, Cleveland, Ohio \\ Duke Power, Charlotte, North Carolina \\ Georgia Power, Atlanta, Georgia \\ New York State Electric \& Gas, Binghamton, New York \\ Salt River Project, Tempe, Arizona \\ Tennessee Valley Authority, Chattanooga, Tennessee
}

These companies are evaluating both inductive and conductive charge stations in demonstrating electric vehicle technology to the public in their region. Because K-State's work with EHV Corp led to the first commercial charge station using advanced smart card technology (microprocessor based "chip cards"), these utility companies are also evaluating advanced billing systems that are expected to revolutionize the way Americans pay bills in the not too distant future.

\section{Billing Systems}

Kansas State University, as part of its effort to evaluate infrastructure for electric vehicles, has been looking into billing systems and how they would apply to advanced technology alternate fuel vehicles. As research progresses, information has been gathered from several countries involved with advanced billing systems and they include France and Canada. Billing systems are being evaluated on the merit of "fitting" and growing with the United States present day "credit card" system. It now appears that in the next three to five years smart card technology will replace credit cards as the card of choice. Kansas State University wants to evaluate and expand the opportunity for the use of smart card applications in the alternate fuel vehicle and utility industry. A number of pilot projects are being considered to integrate parking and charging features in major cities through the use 
of smart card technology. K-State, along with its utility participants, is looking forward to implementing this advanced billing technology into the American marketplace. 


\section{PROCUREMENT OF NEW VEHICLES}

\section{Chevrolet S-10 Vehicles}

The Kansas Electric Utilities Research Program, in participation with the Department of Energy's Site Operator Program, has had its ups and downs during this years program in trying to procure new vehicles. To date, much of the same technology has been in the market place for the past three years. The Site Operator Program has a number of each manufacturer's vehicles with each manufacturer trying to sell additional vehicles to those who have not bought a specific model. This effort is doing little to advance the technology or improve the opportunity to develop a reliable vehicle.

Towards the end of this reporting period it looked as if the Big Three might actually produce large numbers of electric vehicles. One player that has emerged into the field of electric vehicles is Troy Design \& Manufacturing (TDM), of Redford, Michigan. TDM routinely, under contract to the automotive giants, produces concept vehicles, production vehicles, and tooling and assembly lines for production vehicles. TDM has over 1,000,000 square feet of production facility in Michigan. Clearly, this company has the capacity and capability to perform the task of producing a state-of-the-art electric vehicle. During the latter part of this reporting period, the Kansas Electric Utilities Research Program ordered four Ford Ranger Electric Vehicles from TDM. The first vehicle is scheduled for delivery not later than December 31, 1995 and the other three vehicles are scheduled for delivery not later than May $1,1996$.

The Kansas' research program looks forward to the receipt of these advanced design vehicles. Expectations are high, time will determine if we have again over anticipated what can be achieved. 


\section{SUMMARY/CONCLUSION}

With the collapse of national organizations and companies in the EV movement and with the withdrawal of manufacturers committed to delivering quality EV products, the Kansas' electric vehicle program has suffered setbacks. At the same time, there is a renewed belief, for many reasons, that the Big Three or its appointed QVMs will step forward and produce electric drive technology products. If they fail the two Soleq EVcorts, purchased as one of our program's first EV products, continues to prove the "real" viability of electric drive technology. Recognizing that electric drive technology can improve the range of a vehicle and reduce the smog validates why we should continue to work for change. Regardless of the fuel source, regardless of whether the drive is alternating or direct current drive, adapting the next generation vehicle to electric drive will maintain if not dramatically improve the environment, increase significantly the driving range derived from a single BTU of energy, and thereby improve our economy on both counts. It is important that support is provided to companies like Soleq as they represent the "seed" from which other important activities will sprout.

With assistance from organizations like the Kansas Electric Utility Research Program, individual Kansas' utilities, and Kansas corporations, Kansas State University is committed to the management of the electric vehicle program. The "first generation" conductive charge stations, fostered at this institution, are being redesigned to meet tomorrow's electric vehicle requirements. At the same time, KSU's involvement in the Site Operator Program has made all participants look at the "system" to determine where and what other areas can be improved. KSU's program has introduced "new technology chip cards" that can be used in recharging electric vehicles. Existing credit card systems are and will be unacceptable for use with electric vehicle systems. Further, chip cards or smart cards, as they are commonly referred to, can go way beyond the simple application of exchanging money for energy. These cards can be "programmed" with a certain "personality" that matches the product they are being used with. Thus, the cards can "test" systems, validate proper user use, "record" extreme conditions that can be used to validate warranty claims, and many more important and "local" features while allowing controlled information over great distances. Further, this smart card technology application is just the "ticket" that works with an evolving infrastructure required by electric vehicles. No one has to argue about how to interface between conductive or inductive systems, no one has to argue about how to handle the controller aspects of DC versus AC systems; the smart card can be the "common thread" in different systems. Now that VISA and MasterCard have announced their plans to implement a "chip card" product within the next five years, the growth of a payment infrastructure capable of handling EV needs is assured. The real question is, can the EV industry continue to move forward and take advantage of new technology. If not, it is doomed to failure!

During the next quarter, Kansas State University's program expects to receive one electric vehicle from Troy Design \& Manufacturing. This vehicle will be brought into the program for the specific purpose of developing test protocol. The test protocol is to be used nationally as a way of evaluating future commercial electric vehicles or electric vehicle subsystems that 
are expected to be marketed in the next year or two. Kansas State University will be working with Troy Design, Ford Motor Company and hopefully the Department of Energy and the Idaho National Laboratory to develop test protocol.

Kansas State University would like to thank its contributors and participants for their past, present, and future support of this program. 